\title{
SOBRE EL DERECHO COMO «TÉCNICA»O «TECNOLOGÍA» Apostillas a una polémica entre dos visiones cientificistas sobre las posibilidades del discurso jurídico
}

n un número anterior de DOXA presenté un estudio donde, entre otras cosas, me referí en forma crítica a las observaciones que acerca de Kirchmann formula $\mathrm{M}$. Atienza en su Introducción al Derecho ${ }^{1}$. La tesis de Atienza es que, si se tiene en cuenta -como a su juicio, es lo correcto- que «la jurisprudencia es una técnica [no una ciencia], los argumentos de von Kirchmann se vuelven, sencillamente, impertinentes» (op. cit., pág. 281 -cursiva mía, E.P.H.-). Sólo después de tener ya completamente redactada la versión original de dicho estudio mío llegué a advertir que, además de lo señalado por Atienza en ese libro, él había efectuado ulteriormente algunas aclaraciones al respecto; las formuló ante críticas que le dirigió, precisamente en cuanto a la diferencia entre «ciencia» y «técnica» jurídicas. R. J. Vernengo ${ }^{2}$. Aun sin entrar en todos los detalles de este intercambio de ideas entre Atienza y Vernengo, deseo referirme a ciertas cosas que allí se señalan, pues tienen relación muy directa con lo examinado por mí.

Ante todo, me importa subrayar que nada de lo expuesto por Atienza en su Respuesta a Vernengo le hace perder justificación a las puntualizaciones que efectué en mi estudio. Aunque en general estoy

${ }^{1}$ Enrique P. Haba, «Kirchmann sabía menos... ¡pero vio mejor!» Vigencia de un antiguo diagnóstico, más algunas observaciones (que no son simpáticas) sobre la actual Teoría del Derecho», en Doxa-14 (1993), págs. 269-317. El comentario sobre lo que dice Atienza se encuentra entre las notas 10 y 13; cf. también las notas 27, 33, 38 y 50. Manuel Atienza, Introducción al Derecho, Barcanova, Barcelona 1985; cf. allí esp. las págs. 279-282.

${ }^{2}$ Roberto J. Vernengo, «Ciencia jurídica o técnica política: ¿Es posible una ciencia del Derecho?», en Doxa-3 (1986), págs. 289-295. Manuel Atienza: «Sobre la Jurisprudencia como técnica social. Respuesta a Roberto J. Vernengo», en Ibid., págs. 297-311. Roberto J. Vernengo: «Réplica a la respuesta de M. Atienza», en Ibid., págs. 313-314. 
de acuerdo con lo que aquel destaca en sus aclaraciones, donde incluso recurre al mismo libro de Bunge utilizado en mi propia crítica $^{3}$, pienso que estas en modo alguno invalidan los dos reparos principales que le hice: a) que lo señalado por Kirchmann NO es «impertinente», sino todo lo contrario, para el centro mismo de la discusión acerca de lo que el derecho pueda ser como «técnica» o «tecnología»; b) que la distinción entre «técnica» y «tecnología» constituye una presentación mucho menos nítida que aquella de Bunge, entre «tecnología» y «seudotecnología», máxime si es cuestión de advertir sobre las insuficiencias teoréticas que caracterizan al discurso normal de los juristas ${ }^{4}$. Ahora paso a ocuparme de algunos aspectos de la polémica Vernengo-Atienza.

Vernengo llama la atención sobre la diferencia entre las técnicas cientificas y «otro tipo de técnicas, como las primitivas utilizadas en prácticas religiosas, en las artes y artesanías o, inclusive, en la vida cotidiana» (pág. 293); a partir de ahí, concluye que si la jurisprudencia fuera una técnica, lo sería precisamente del primer tipo (ibid.). Es correcto, desde luego, distinguir en general, como pide Vernengo, entre esos dos tipos de «técnicas». Y si el derecho perteneciera en efecto al primero de ellos, no daría lugar a ninguna confusión importante llamarle «ciencia». Pero toda la cuestión es justamente esa: ¿constituye el discurso de los juristas, en realidad, un procedimiento de tal tipo? Como se ve, Vernengo cree que sí, aunque no deja de reconocer que también hay allí de lo otro, pues «muchas de las técnicas utilizadas por los juristas no tienen el carácter de una técnica científica, manteniéndose al nivel de prácticas más primitivas» (pág. 295; cf. también pág. 314: «no dudo que hay cosas producidas por los juristas que ni siquiera alcanzan el nivel de aquellos libros de cocina...»). En cuanto a la naturaleza de dicha «ciencia», termina afirmando: «algunas de las cosas que hace el jurista lo asemejan al político; otras, lo acercan al ingeniero, al médico, al psicólogo. ¿Por qué poner todo bajo un único rasero?» (pág. 295; cf. también pág. 314).

Pienso que, planteadas las cosas de esa manera, el asunto prácticamente se diluye. Tiene razón Vernengo al decir que no hay por qué «poner todo bajo un único rasero»... Bueno, ¿pero qué es lo que estamos discutiendo entonces? Si de lo que se trata es de ver, frente

${ }^{3}$ Mario Bunge, Seudociencia e ideología, Alianza Editorial (AU 440), Madrid, 1985. Mi referencia a Bunge, en «Kirchmann...» (supra nota 1), se encuentra allí a la altura de la nota 11.

${ }^{4}$ Cf. «Kirchmann...» (supra nota 1): apartado II. B y passim. 
a cada discurso jurídico en particular o a un grupo de ellos, si éste es más bien de sello «político» que «ingenieril» o acaso «médico», «psicológico», etc., ¿qué sentido tiene sostener que la jurisprudencia es en general «científica», o negarlo? Tenemos que basarnos en algún concepto general de ciencia al examinar dicha pregunta, para que en función de él podamos «medir» la naturaleza de unas u otras actividades jurídicas (aun sin necesidad de negar que existen diferencias entre estas). Sólo con base a tal concepto se puede llegar a alguna conclusión sobre si el Derecho, todo él o en su mayor parte, es o no es ciencia. Mas no está claro cuál sea tal concepto en la posición de Vemengo, y mucho menos qué pruebas hay de que la experiencia jurídica real se adecúe a él.

Las debilidades, o por lo menos las faltas de precisión, del punto de vista de Vernengo han sido bien advertidas por Atienza. Éste comienza por aclarar que, aunque hallemos una «estrecha interconexión existente entre la ciencia y la técnica... ello no significa que haya que renunciar a diferenciar la una de la otra» (pág. 299)

Después pone el dedo en la llaga, señala el punto clave, aquello de lo que Vernengo prefiere apartar la vista: «La dogmática jurídica mantiene pocas, y poco profundas, relaciones con la ciencia, y desde luego, no me parece que pueda decirse que se basa en alguna(s) ciencia(s) en particular, sino más bien en una combinación de experiencia, sentido común, conocimiento ordinario, etc.» (pág. 307 -subrayados míos, E. R H.-) ${ }^{6}$. Aun admitiendo que algo de «ciencia»-algún «parecido de familia» (Wingenstein), dije yo ${ }^{7}-$ puede contagiársele a la jurisprudencia, Atienza acota que a él (y también a mí) le «gustaría saber cuáles son esas actividades presuntamente científicas [a que se refiere Vemengo] y qué peso tienen en el conjunto de la dogmática» (pág. 309 -subrayados míos, E. P. H.-). La carga de esta prueba debe recaer, naturalmente, en aquellos que como Vernengo, afirman la existencia de semejante carácter «científico» en el discurso jurídico. Salvo que se prefiera evadir esa responsabilidad inmunizándose contra ella mediante alguna definición estipulativa que sea tan amplia como para abarcar de antemano, por la vía de una petición de principio, hasta razonamientos como los que suelen tener curso en la actividad profesional de los juristas. $\mathrm{Ni}$

${ }^{5}$ Para un esclarecedor análisis de esas diferencias, cf, Atienza (supra nota 2); págs. 300-307. Pero téngase también en cuenta la observación de Michael Mulkay transcrita en «Kirchmann...» (supra nota 1): nora 11 in fine.

${ }^{6}$ No me canso de mencionar la insuperable caracterización efectuada por Radbruch: «una indisoluble mezcolanza de elementos teoréticos y prácticos, cognoscitivos y creativos, reproductivos y productivos, científicos y supracientíficos, objetivos y subjetivos» (Gustav Radbruch, Rechtsphilosophie: cap. 15 in limine).

${ }^{7}$ Cf. «Kirchmann...» (supra nota 1): apartado III. 2. 
Vernengo ni otros autores ofrecen las pruebas pedidas, sino unos juegos de implícitas redefiniciones (persuasivas) del concepto «ciencia» que permiten exonerarse de presentar pruebas.

Mucha razón asimismo tiene Atienza en recalcar cuál es, al fin de cuentas, el motivo de fondo de estas discusiones: «la respuesta -cualquiera que ésta sea- carece de relevancia teórica y quizás no tenga tampoco mucha importancia práctica, pues no es de esperar -como indica Vernengo al comienzo de su comentario- que los dogmáticos vayan a modificar, por el simple hecho de que su actividad se considere o no "científica", la forma de cultivar su disciplina.

Semejante debate no parece cumplir más que una función ideológica (que, de todas formas, tampoco conviene olvidar): la de descalificar o justificar, según los casos, el saber jurídico tradicional, pero sin que nuestro conocimiento sobre el mismo se vea aumentado por ello» (pág. 307) ${ }^{8}$. Atienza tiene la honestidad de reconocer que, por ende, la discrepancia entre él y Vernengo «es más un desacuerdo en cuanto a nuestras respectivas actitudes frente a la dogmática que un desacuerdo de creencias sobre lo que sea la actividad dogmática... Me parece que esa diversa actitud podría expresarse así: Vernengo tiene una actitud más positiva que la mía (aunque la suya no implique una aceptación sin reservas ni la mía una crítica radical) acerca del modo de proceder del jurista dogmático» (pág. 310).

Habiéndome permitido terciar en esta polémica, debo reconocer que también mi propia posición, más escéptica (¿«crítica radical»?) que la de Atienza, responde en última instancia a una actitud. A una que, sobre todo, implica gran desconfianza hacia los mitos que conlleva toda ilusión racionalista respecto a las «construcciones» (Berger/Luckmann) del pensamiento social (cf. Freud, Frank, Schumpeter, Debray, etc.). Sin embargo, aun estando advertido de que el impulso para tomar tal o cual posición es en sí mismo extra-científico, básicamente existencial, «actitud», etc., no creo que de ello se siga que tanto da -jteóricamente hablando!- que se diga una cosa como cualquier otra. Más allá de los motivos personales que a cada quien lo llevan a decir lo que dice, eso que él dice puede ser más cierto o menos cierto, más transparente o más disimulador, etcétera. [Supongo que tanto Vernengo como Atienza y yo mismo estamos de acuerdo, por lo menos, en que hay diferencia entre verdad y falsedad; si no presupusiéramos tal cosa, no estaríamos discutiendo.]

${ }^{8}$ Cf. también «Kirchmann... (supra nota 1): a la altura de la nota 27 y esa misma nota (la cual contiene otras palabras de Atienza sobre el asunto). 
Pues bien, la diferencia esencial entre una posición como la de Vernengo, por un lado, y la de Atienza o la mía, por el otro, es que nosotros dos nos callamos (sea por los motivos que fuere) algo que Vernengo, en cambio, prefiere (sea por los motivos que fuere) remitir al campo del «mejor es no meneallo...». Eso que Vernengo echa a un lado de la palestra, lo que él NO considera digno de una atención principal a la hora de categorizar el discurso de los juristas, sin embargo es, nos guste o no nos guste, una verdad de hecho. Más aún, ella es decisiva para comprender de qué se trata ahí realmente. Y esto, en sí mismo, para nada depende de nuestras respectivas actitudes, ni de que le pongamos o no el rótulo de «ciencia» al pensamiento jurídico. Me estoy refiriendo ni más ni menos que a una comprobación tan notoria como la siguiente: al HECHO de que el discurso corriente de los juristas -jel real!deja de lado conocimientos pertinentes y ciertas bases generales de razonamiento aceptados en la generalidad de las otras disciplinas a las que se llama ciencias. Hasta cabe afirmar que ese discurso SE OPONE propiamente a los paradigmas comunes, de precisión empírica y de orientación antirretórica, que caracterizan a la generalidad de éstas ${ }^{9}$. Tal diferencia esencial puede, claro está, ser valorada como cada quien guste hacerlo, consiguiendo así justificarla o criticarla. Y se puede, también, utilizar (persuasivamente) uno u otro de los muchos significados del término prestigioso «ciencia» para expresar la valoración por la que se optó. No obstante, por más contingentes que sean todas esas valoraciones, y por más convencionales que sean todas las definiciones de ese término, no es lo mismo, en el plano TEÓRICO, decidirse a reconocer dicha diferencia que apartar la vista de ella. Y tampoco esta será ni mayor ni menor, en sí misma, por que la actitud de unos u otros les lleve a recalcarla o a silenciarla. Diferencia objetiva, pues, aunque en efecto sean subjetivas las inclinaciones (actitudes) que a cada teórico lo inciten personalmente a advertirla o pasarla por alto, a confesarla o callarla, a aplaudirla o lamentarla.

Puede decirse, recurriendo al estribillo de Luhmann, que el pensamiento jurídico normal opera mediante una «reducción de la complejidad» del mundo social, en el discurso respectivo. Éste se ocupa precisamente, entre otras cosas, de ponerle una valla -ipeculiar «reducción»!- a la posibilidad de que, para resolver conflictos, se tengan en cuenta unos saberes sustantivos o los métodos de investigación de las ciencias sociales en general (y ni que hablar en cuanto a los de disciplinas científicas más lejanas). O sea, que los «saberes» jurídicos se dirigen, esencialmente, a des-conocer aspectos esenciales de lo que otras ciencias han logrado saber sobre la conducta

${ }^{9}$ Cf. el lugar señalado supra en la nota 7. 
humana, tanto respecto a la de los grupos sociales como a los verdaderos condicionantes de actuaciones individuales ${ }^{10}$. Esos «saberes» consisten en acudir, para aprehender intelectualmente las cuestiones y para resolverlas, a unos discursos que se elaboran con prescindencia de los más elementales conocimientos sobre las «celadas» (Wingenstein) que nos tiende el lenguaje común, plano al que pertenece en su mayor parte cuanto dicen los juristas. Por lo demás, estos ignoran todo, o casi todo, respecto a las bases teoréticas de la construcción de los lenguajes científicos en general.

De la ciencia de los juristas, por eso, lo menos que puede decirse es que ella es algo muy distinto de cualquier otra disciplina científica, aun si la comparamos con las demás ciencias llamadas «blandas». Ninguna definición persuasiva, o no persuasiva (si las hay), de la palabra «ciencia» puede hacer que no existan tales diferencias EN LOS HECHOS, o hacer que la existencia misma de estas dependa de si la actitud de los locutores es favorable a reconocerlas o no. Diferencias que, por tanto, no es exagerado reconocer como plenamente objetivas -si se admite que tiene sentido usar el término «objetividad» para calificar (y distinguir entre) discursos, y sobre todo respecto a los de tipo teorético- ${ }^{11}$.

Por otro lado, quiérase o no, asimismo es de orden teorético -vale decir: no simplemente diferencia de actitudes (la hay), sino también de creencias- una discrepancia, aunque sea menor, entre las conclusiones a que llega Atienza y las mías. Pues si bien las consideraciones descriptivas que Atienza formula sobre el discurso actual de los juristas, creo que en el fondo no difieren mucho, detalles terminológicos aparte, de lo que también pienso yo al respecto, empero él comparte - ¡yo no!- la ilusión cientifista de que sería posible cambiar sustancialmente ese discurso. Según él, en efecto, existiría «la posibilidad de modificar la forma habitual de la elaboración dogmática...» (pág. 309), Y agrega: «frecuentemente, no alcanza (el proceder dogmático) los niveles de racionalidad a que cabría aspirar dado el estado de desarrollo actual de las ciencias y de las tecnologías. Precisamente por eso considero inte-

${ }^{10} \mathrm{Cf}$. «Kirchmann...» (supra nota 1): notas 9 y 14 , y apartado II. B.

${ }^{11} \mathrm{Cf}$. también, análogamente, las precisiones sobre la objetividad de lo racional efectuadas al final del Excurso en mi estudio «Racionalidad y método; ¿es eso posible?». [Una versión ampliada de dicho estudio, el cual se publicó originalmente en Doxa 7 y 8 (1990), apareció en la Revista de Ciencias Jurídicas de la Universidad de Costa Rica, n. ${ }^{\text {os }} 66$ y 67 ; el mencionado Excurso está sólo en ésta, págs. 127-133 del n. ${ }^{\circ}$ 66]. 
resante y pertinente proponer modelos alternativos al paradigma de la dogmática actualmente vigente» (pág. 310 -subrayado mío, E.P.H.-). Yo pienso, más bien, que tales «modelos alternativos» tienen su destino confinado a los congresos de Teoría del Derecho, a revistas y libros de la materia, o a los proyectos de investigación cuyo financiamiento requiere conjurar en las autoridades la ilusión tecnocrática de que así se puede contribuir a hacer más «científico» el derecho ${ }^{12}$.

Para esos «modelos alternativos», sea cual fuere su contenido, es demasiado magra, por no decir nula, la posibilidad que tienen de llegar a ser conocidos, y mucho menos adoptados, por los juristas corrientes. Claro que esta afirmación mía, un pronóstico, no es algo que se pueda comprobar ni refutar sino en el futuro (mejor dicho: comprobada no podrá ser nunca, ya que el futuro siempre permanece abierto). No diré, pues, que es absolutamente imposible que unos «modelos alternativos» lleguen alguna vez a ser adoptados en la actividad jurídica normal. Así y todo, no veo en qué pueda basarse Atienza para creer, si es que lo cree, que tal cosa sea verdaderamente probable, habida cuenta de todas las experiencias históricas disponibles, con las cuales sigue concordando en la actualidad el pensamiento y la conducta de los juristas prácticos. También habría que discutir -pero es otro asunto- si semejante ciencia, supuesto que se consiga elaborarla y además ponerla en práctica normalmente, tendría consecuencias sociales más deseables que el discurso jurídico actual: ¡remember los mundos de Orwell y Huxley!

Me parece, dicho con todos los respetos, que los afanes cientificistas respecto al derecho -y en esto Atienza no está muy lejos de Vernengo y de la gran mayoría de los iusmetodológicos actuales responden básicamente a un wishful thinking suscitado por la función que en nuestras sociedades tiene la fe en la ciencia, como relevo o complemento de las cosmovisiones religiosas ${ }^{13}$. Si digo «fe» en la ciencia, ahí no me estoy refiriendo, por supuesto, a la confianza, justificada, en los resultados empíricamente acreditados de unas u otras disciplinas científicas, o a la eventualidad de llegar a obtener nuevos resultados de tipo similar en las mismas esferas. A lo que me refiero es a la actitud mitologizante de imaginarse que la ciencia, sus métodos, son un cúralo todo: que estos sirven hasta para arreglar cuestio-

${ }^{12} \mathrm{Cf}$. también «Kirchmann...» (supra nota 1): lo relativo a Atienza, en la nota 50.

${ }^{13}$ Se trata, específicamente, de una mitología del tipo tecnomorfo: la ilusión, en este caso, de que la realidad social está conformada, o puede llegar a ser conformada, a la manera de lo que hace un «técnico» -artesanos, ingenieros, etc.- al fabricar los objetos de su especialidad, esto es, elaborarlos de acuerdo con sus propios planes. Cf. Ernst Topitsch, Erkenntnis und Ilusion. J. C. B. Mohr (Paul Siebeck), Tubinga, 1988. 
nes de la conducta (convivencia) humana que ningún discurso científico ha podido jamás solucionar en general -ni siquiera aproximadamente- en la práctica. Tampoco la ciencia contemporánea está en condiciones de ofrecer, ni hay perspectivas de que pueda llegar a ello, unas técnicas (o tecnologías) realistas para resolver normalmente estos asuntos, vale decir, lo esencial de las cuestiones sociales y los problemas psicológicos-existenciales de la vida personal de cada quien. Pero distintas especies de «fe» (no sólo la religiosa) proveen, contra la angustia que provocan ciertas inseguridades inevitables y los problemas insolubles de la vida, un asidero en nuestra imaginación para permitimos creer que esas inseguridades y esos problemas son obviables mediante alguna solución milagrosa: por ejemplo, con la ciencia de la computación o la «racionalidad» del derecho.

Cuando semejantes milagros se esperan de la metodología científica, estamos ante un tipo propio de mitos, muy en boga en el campo de las ciencias sociales ${ }^{14}$. Y el gremio de los juristas no es menos sensible a estas mitologías que cualquier hijo de vecino... ¡ni que los hombres de ciencia en general!. Cabe reconocer, no obstante, que respecto a la actividad jurídica en sí misma, esos mitos resultan algo más inofensivos que en otras esferas. Cuando se predican en relación con el pensamiento jurídico, simplemente proporcionan tema para la conversación entre iusmetodólogos. Y si hay legos interesados en ello, podrán confortarse pensando que por ahí, en medio de esos discursos raros, debe de estar oculta la varita mágica capaz de transformar en inmaculadas computadoras para diskettes sociales a los egresados de la Facultad de Derecho. A Kirchmann o Frank, o al propio Kelsen, no hubiera resultado tan sencillo, claro está, hacerles paladear estos anzuelos. Ni siquiera, estoy seguro, por más que vinieran empanados con unos adobes bien «científicos».

${ }^{14}$ De este mito como ideología profesional de los científicos sociales me ocupo en un estudio mío todavía inédito: «Imposibilidades para las ciencias de lo humano. Sobre la concepción "misionera" de las ciencias sociales como (auto)justificación profesional».

${ }^{15}$ Véase, por ejemplo, la nefasta influencia de tales ingenuidades en la programación del régimen para cursos universitarios: cf. Enrique P. Haba, «De la fantasía curricular, y sobre algunas de sus precomprensiones tecnocráticas», en Revista de Ciencias Jurídicas n. ${ }^{\circ} 56$ (mayo-agosto 1986, págs. 11-48, Universidad de Costa Rica. He escrito también una continuación de ese estudio, inédita: «Tres discursos para la Escuela de Ciencias Políticas. De la fantasía curricular (II): la retórica de los "objetivos"»).

\section{DOXA 17-18 (1995)}

